\title{
Analysis of Teaching Techniques and Scheme of Work in Teaching Chemistry in Rwandan Secondary Schools
}

\author{
Edwin Byusa $^{{ }^{*}}{ }^{\text {Edwige Kampire }}{ }^{2}$, Adrian Rwekaza Mwesigye ${ }^{3}$ \\ ${ }^{1}$ African Centre of Excellence for Innovative Teaching and Learning Mathematics and Science (ACEITLMS), University of Rwanda \\ College of Education (UR-CE), RWANDA \\ 2 University of Rwanda College of Education (UR-CE), Department of Mathematics, Science and Physical Education, RWANDA \\ ${ }^{3}$ Mbarara University of Science \& Technology (MUST), Department of Educational Foundations and Psychology, UGANDA
}

Received 8 December 2019 - Accepted 4 February 2020

\begin{abstract}
This study aims at determining the effect of the pedagogical technique most frequently used while implementing the competency-based curriculum (CBC) in teaching chemistry in senior two (S2) classes (age range 14-16) and the teachers' alignment with the scheme of work. It was conducted in 10 selected Rwandan secondary schools using a teacher survey, teacher interviews and the Classroom Observation Protocol for Undergraduate STEM (COPUS) in the period from 27 May to 8 July 2019. The result of the analysis reveals that teaching chemistry using group work-related techniques that engage more learners does not have any relationship to teachers moving slowly compared to the scheme of work of $\mathrm{S} 2$ chemistry. Therefore, this study recommends more support for teachers to use active learning techniques in teaching chemistry in S2 for the effective implementation of the CBC.
\end{abstract}

Keywords: chemistry subject, $C B C$, scheme of work, senior two chemistry classes, teaching technique

\section{INTRODUCTION}

Chemistry teachers everywhere employ different teaching techniques in secondary chemistry classes; some may work well while others may not. Students also have different learning capacities and different preferences in learning techniques and styles. The important issue in the school science classroom has been the focus on presenting information through chalk and talk, or passive learning; students receiving this kind of instruction remain inactive during classroom activities and feel that chemistry knowledge is fixed and that no further action is required (Chee \& Tan, 2012). Freeman et al. (2014) revealed that students in passive classes are 1.5 times more likely to fail than students in active classes. To respond to the above issue and facilitate the smooth learning of science, including chemistry, much effort has been put into a variety of activities that aim to help teachers shifting from teacher-centred pedagogy to learner-centred pedagogy, including many active learning and teaching techniques for teachers to use during the teaching and learning process. One study proposed that teachers use the technique that was selected by most students prior to the start of the lesson (Kousa, Kavonius \& Aksela, 2018).

Active learning is a process that gives full opportunities and enough time for students' interactions by engaging them to construct positive understanding and skills independently and assess their progress themselves in order to complete a task. Some of the techniques that involve active learning include "conceptual change strategies, cooperative/collaborative learning/group work of all kinds, technology-enhanced learning, inquiry-based learning, problem-based or casebased learning, discovery learning and think-pair-share or peer instruction" (Michael, 2006, p. 160). At this time, the active learning techniques that are prioritized in science education are process-oriented guided inquiry learning, peer-led team learning and problem-based learning (Eberlein et al., 2008; Kristen, Malinda, Monica, \& Kendra, 2017). For instance, different engaging teaching techniques have been used in chemistry classes. According to Brandt et al. (2001), concept visualization had a positive impact on chemistry learning outcomes in 


\section{Contribution to the literature}

- $\quad$ This study demonstrates that during the implementation of the $\mathrm{CBC}$, prioritizing passive learning techniques by teachers does not mean that teachers are likely to cover the chemistry content in the given time period of the school calendar.

- This study demonstrates again that prioritizing active learning techniques does not make teachers slower in covering the chemistry content in the given time period of the school calendar.

- This study suggests that there should be more support for teachers to use active learning techniques and that teachers should receive more continuing practical training in these techniques so that they know that putting students in groups is not in itself a sufficient active learning technique.

secondary schools in Flanders for the chemistry subtopic of electrochemistry, while concept mapping was found confusing to students trying to acquire the required knowledge, skills and practice. However, another study conducted in Turkey and India in 2013 recommended that concept mapping was a more effective teaching strategy for students' performance than conventional techniques for teaching chemistry in classes at the Class IX level (KILIC, 2013).

The comparison of the two concept mapping techniques reveals that a high-directed concept mapping technique generates better student performance results than low-directed concept mapping (Ruiz-Primo Schultz, Li \& Shavelson, 2001). Students construct chemical concepts at their own paces, and sometimes this chemical concept construction is based on students' daily experiences. Students should, therefore, be given the chance and enough time to develop a good understanding of a chemical concept during the chemistry teaching and learning process (Stavridou \& Solomonidou, 1998). Computer-based learning is another technique used in the chemistry teaching and learning process in secondary schools for several chemistry-related subtopics. Research conducted in German secondary schools revealed that the chemistry subtopics of chemical bonding, chemical equilibrium, the structure of matter, organic reaction mechanisms and electrochemistry can be taught using computer-based learning techniques (Pietzner, 2014). However, according to Paulson (2009), students do much better in the organic chemistry subtopic when they are able to have many open-ended discussions during the teaching and learning process as opposed to only having the teacher talk. In Indonesia, it was found that mobile game-based learning had a positive impact on student performance in chemistry, but only for students with high levels of academic independence (Cahyana, Paristiowati, Savitri \& Hasyrin, 2017). Another study was conducted in selected secondary schools in Nigeria demonstrated that the teaching technique of giving students a particular task to work on during their free time, individually or in a group and within a given time frame or self-determined time generated better academic achievement results for secondary students in practical chemistry than other teaching techniques such as lecture/demonstration or inquiry-based teaching techniques did (Sola \& Ojo, 2007). In the same country, another study revealed that the cooperative learning technique, which improves cooperation among students as they work together in a group and where no individual is held to account if something goes wrong, was found better in reducing students' anxiety in chemistry classes and produced better performance than when the chalk and talk technique was used (Oludipe \& Awokoy, 2010).

Rwanda has not been left behind in the worldwide need for education systems that allow students to be fully engaged in the whole process of learning and teaching as individuals or in groups and address learners' individual needs and expectations. Through Rwanda Education Board (REB), Since January 2016, all levels of general education schools, pre-primary, primary and secondary, in Rwanda use the CBC, which is a learner-centred curriculum. The CBC clearly states the aspects related to each subject, including chemistry, to be developed by learners in terms of knowledge, skills, attitudes and values through the active teaching and learning techniques including role play, projects, quizzes, oral questioning, field visits, debates, paired and group work, problem-solving, individual work, investigations, assignments, practical work, tests, presentations and discussions (REB, 2015). The CBC is important in supporting the aim of the Government of Rwanda (GoR) to develop a knowledge-based society (Lackamp, 2016). Learners should interact and work together in acquiring needed skills, knowledge, attitudes and values during the CBC implementation (Ndihokubwayo \& Habiyaremye, 2018). This active and mutual support in learning will result in effective implementation of the $\mathrm{CBC}$, which will support the government's aim stated above. It is for this endeavour that the REB (2016) provides opportunities for all inservice teachers to be involved in school-based training on CBC practice. On top of that, the scheme of work is prepared mainly by teachers themselves to make sure that the content to be taught in a particular period is covered (Musingafi, Mhute, Zebron \& Kaseke, 2015).

Despite the above efforts of the GoR towards improving the quality of education by effective $\mathrm{CBC}$ implementation in schools, the $\mathrm{CBC}$ has not been 
effectively implemented. This has been confirmed by joint REB and Japan International Cooperation Agency (JICA) research that concluded that teachers were not well instructed in the use of $C B C$ and were not confident to implement it effectively (REB, 2016). This has led to poor teaching techniques, poor large-classroom management and, consequently, a lack of student engagement and the generation of equivocal understanding of chemistry concepts (Maxwell, Lambeth \& Cox, 2015), which constitutes a major challenge to attaining a knowledge-based society (REB, 2015). For this reason, this study was conducted to find out how the selected teaching techniques by senior two (S2) chemistry teachers from 10 selected schools in Rwanda were affecting the implementation of CBC by considering the scheme of work of S2 chemistry in the Gasabo District.

\section{Research Questions}

This study examines whether using active learning techniques in teaching chemistry at the S2 level leads to slower teaching and not covering the chemistry content as planned by the scheme of work. The following are the specific research questions that guided this study:

1. Are teachers of $S 2$ chemistry prioritizing active learning techniques?

2. To what extent do S2 chemistry teachers follow the scheme of work as planned?

\section{METHODOLOGY}

This study employed a deductive research design by testing the behaviourism learning theory (Bitektine, 2008) to determine how much the chemistry teachers had shifted from teacher-centred to learner-centred teaching methods (Imenda, 2018) during the implementation of the CBC in 10 selected secondary schools in the Gasabo District of Rwanda. Both qualitative and quantitative methods were used to understand the current situation in selected secondary schools in chemistry education (Creswell \& Garrett, 2008). The 10 schools were selected during the consultation meeting with education officials in the district on 22 March 2019. With the purpose of having all localities (urban, suburban and rural areas) of the Gasabo District represented and considering schools that are part of both 12- and 9-years basic education in Rwanda. All S2 chemistry teachers of those schools and their students were, therefore, part of this study. All the 10 schools do not have a proper scientific laboratory, only small science kit, movable laboratory facilities are available at schools since 2011, but currently, they do not have chemical reagents, only basic apparatus are available. Again, all 10 selected schools have a small library with both teachers' and learners' subject-matter books which are designed as per the CBC.

The S2 chemistry teacher survey, teacher interviews and the classroom observation were conducted in the period from 27 May to 8 July 2019, at the 10 selected schools. Both teacher survey and interview guide were found valid by authors after careful analysis of those tools against the objectives of the study and consultation with four chemistry teachers and one postgraduate student in chemistry education. The Classroom Observation Protocol for Undergraduate STEM (COPUS) was used to observe teachers in their normal classroom activities. The validity and reliability of the COPUS were established a long time ago (Smith, Jones, Gilbert, \& Wieman, 2013) and it was used with confidence even though the context differs, observers went through different online support on how to use it. Teachers were each observed more than three times, then after the reference dates were selected in order to compare how the teachers were aligned with the scheme of work.

The first research question was tested using all the three tools mentioned above, the survey had 11 questions on the pedagogical techniques that teachers most commonly used in teaching chemistry, and the teacher interviews had three questions on the same aspect. The COPUS was used during the classroom observation to test the second research question, by checking teachers' and learners' activities during the chemistry lesson. Then, we combined COPUS' observation codes to conclude on active and passive learning. Then the chemistry topic thaught at the reference date.

The key observation codes were grouped in different categories during the analysis. First, the codes were grouped together in order to classify students' activities into passive and active: Active learning was grouped into answering (AnQ), asking (SQ), whole-class (WC), presentation (SP), working group (WG) and other groups (OG). Passive learning was grouped using the following COPUS key observation codes: listening (L) and thinking (Ind). Second, for teacher's activity, the COPUS key observation codes were grouped into the two categories of presenting and guiding: Presenting included lecturing (Lec), writing (RtW) and Demo/Video (D/V), and guiding included follow-up (Fup), posing question (PQ), answering question (AnQ), moving (MG) and one-on-one (1o1) (Lund et al., 2015).

Based on the research questions, both quantitative and qualitative data were analysed. The analysis of the quantitative data established the relationship between the teaching technique used and alignment to the scheme of work, while the qualitative analysis described the observable behaviour of the teachers and students while teaching and learning chemistry in S2.

The ethical issues were considered (including confidentiality, privacy and security of data collected) related to carrying out this study. The ethical approval was granted by the Research and Innovations Unit of the University of Rwanda, College of Education before 
starting the field data collection. Consent was obtained in all schools, and the Gasabo District authorized this research.

\section{RESULTS AND DISCUSSION}

The learner-centred teaching and learning approach is well known in all Rwandan schools since the implementation of the CBC in 2016. However, making the teaching and learning process learner-centred in a real sense is still an issue that requires observation. Another issue is conceptions about teaching techniques when using group work-related activities. Some teachers believe that just using group activity itself when teaching is enough to show that they are successfully implementing the $\mathrm{CBC}$. Other teachers believe that simply putting learners in groups means that active learning has taken place. This has been confirmed by the results of the teacher survey and teachers interviews. However, the COPUS observation revealed that the practice in the classroom is far from what is being claimed by teachers in interviews and the survey.

The results of the teacher survey, self-reported questionnaire and teacher interviews confirmed that $60 \%$ of S2 chemistry teachers from the selected schools used active learning technique on a daily basis, and the remaining $40 \%$ of teachers used it at least once a week (Figure 1). All teachers from the selected schools claimed to be using active learning techniques while teaching S2 chemistry classes as it is a requirement in implementing $\mathrm{CBC}$, saying that the techniques they most commonly used were: group activity, group discussion, group work, group work and presentation, think-pair-share, and other learner-centred methods. However, the real practice in classrooms was dominated by teachers, using methods such as lecturing and writing on the board and then trying to insert a small activity to be done in a group that did not engage all learners, did not facilitate the construction of knowledge and was sometimes limited to a question-and-answer session. This shows that teachers were not aware of what the learner-centred approach is all about. Other studies in other areas have also shown that chemistry teachers have been influenced by the teacher-centred approach (Eilks, Prins \& Lazarowitz, 2013), the same thing that occurred was observed in the Rwandan study: Classroom practice did not reflect actual learner-centred teaching approaches.

Teaching chemistry using group work as a teaching technique has been shown to be better than conventional techniques in terms of students' academic performance (Michael, 2006). Group activities of all kinds can be grouped into three main approaches: problem-based learning, collaborative learning and cooperative learning (Davidson \& Major, 2014). Therefore, teachers in selected schools should, therefore, be supported to take advantage of group-related activities to make the classroom fully active and engaged. The role of the teacher should remain a guiding role only during the implementation of the CBC.

It has also been found that the spirit of using active learning techniques, together with teachers' selfassessments about using active learning related techniques in teaching chemistry, do not have anything to do with the number of years of teaching experience and frequency of using them (Table 1).

Using COPUS for classroom observation, this study found that teachers whose main teaching technique was chalk and talk were on track per the scheme of work (Table 2). The most common student activity (75\%) was listening to the teacher and taking notes followed by students answering a question posed by the teacher with the rest of the class listening. Eighty-one per cent of students' activities were passive.

Most teachers who were behind the scheme of work were found to be trying to engage students in their teaching techniques, and the same was observed for those that were in advance (Table 2). Figure 2 shows that there was not any relationship in S2 chemistry teaching technique and alignment with the district chemistry scheme of work. As Table 2 shows, despite what the teachers reported, the reality in class was that they were prioritizing passive learning.

Even though in the interviews and the teacher survey the teachers all claimed that they were using active learning techniques, classroom observation using COPUS revealed that students continued being passive in the classroom. In some of these classes, teachers were still behind the scheme of work, which is contrary to the belief that using passive techniques will allow teachers to cover the chemistry content within the given period of time (Tenaw, 2015). 


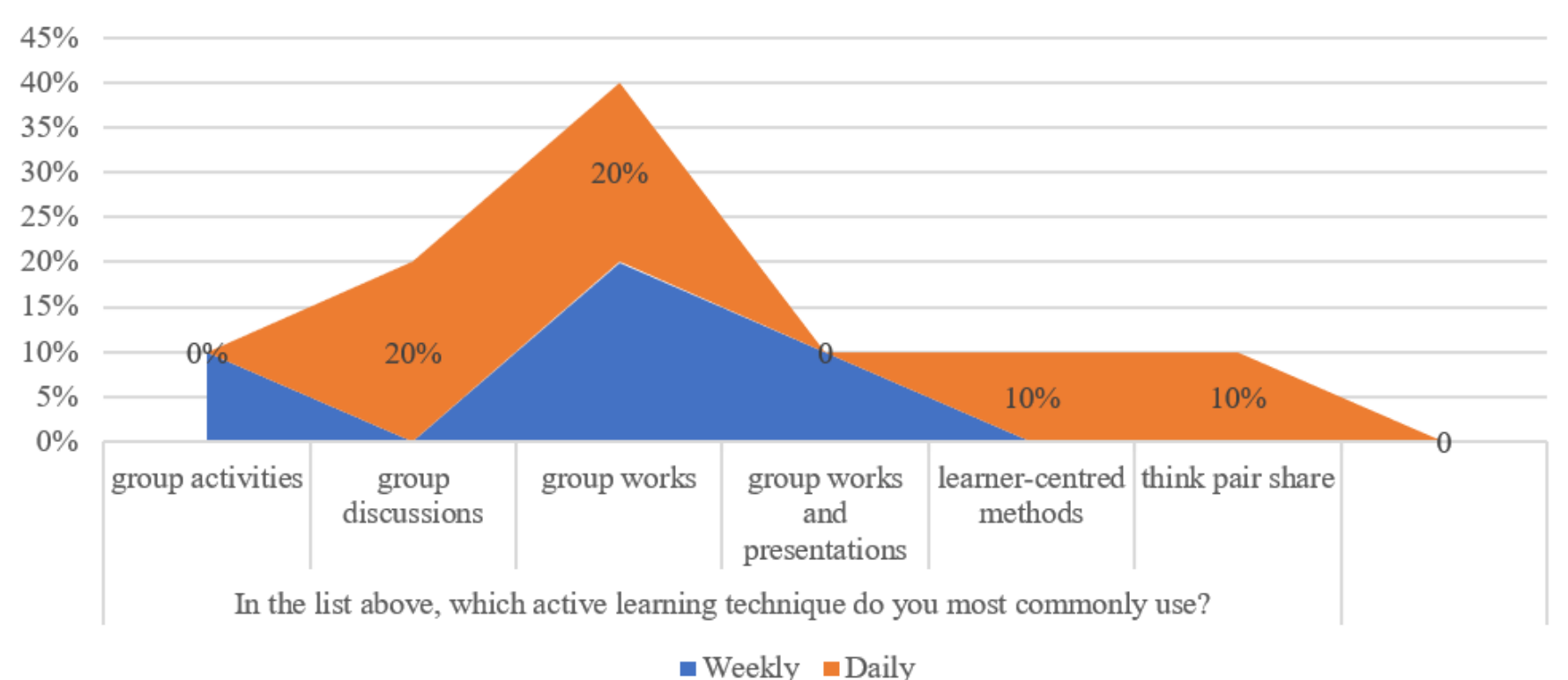

Figure 1. Teachers' self-reported frequency of using active learning techniques and most commonly used techniques

Table 1. Teachers' self-reported frequency of using active learning techniques, confidence and teaching experience

\begin{tabular}{|c|c|c|c|c|c|}
\hline \multirow{2}{*}{\multicolumn{3}{|c|}{ Frequency of use of active learning and teaching technique }} & \multicolumn{2}{|c|}{$\begin{array}{l}\text { Teacher's self-assessment or peer-assessment of } \\
\text { using active learning and teaching technique }\end{array}$} & \multirow[t]{2}{*}{ Total } \\
\hline & & & Intermediate & Expert & \\
\hline \multirow{5}{*}{ Weekly } & \multirow{4}{*}{$\begin{array}{l}\text { Number of } \\
\text { years teaching }\end{array}$} & 2-3 years & $0 \%$ & $10 \%$ & $10 \%$ \\
\hline & & $4-5$ years & $10 \%$ & $0 \%$ & $10 \%$ \\
\hline & & $6-9$ years & $10 \%$ & $0 \%$ & $10 \%$ \\
\hline & & 10-19 years & $10 \%$ & $0 \%$ & $10 \%$ \\
\hline & Total & & $30 \%$ & $10 \%$ & $40 \%$ \\
\hline \multirow{4}{*}{ Daily } & \multirow{3}{*}{$\begin{array}{l}\text { Number of } \\
\text { years teaching }\end{array}$} & $0-1$ year & $0 \%$ & $10 \%$ & $10 \%$ \\
\hline & & 6-9 years & $20 \%$ & $10 \%$ & $30 \%$ \\
\hline & & 10-19 years & $20 \%$ & $0 \%$ & $20 \%$ \\
\hline & Total & & $40 \%$ & $20 \%$ & $60 \%$ \\
\hline
\end{tabular}

Table 2. Comparison of both teachers' and students' activities with alignment with the scheme of work of chemistry in S2 for 2019 school year

\begin{tabular}{|c|c|c|c|c|c|c|c|}
\hline \multirow{2}{*}{$\begin{array}{l}\text { Teacher } \\
\text { code }\end{array}$} & \multirow{2}{*}{$\begin{array}{l}\text { Reference } \\
\text { date }\end{array}$} & \multirow{2}{*}{$\begin{array}{l}\text { Teaching topic on the } \\
\text { reference date }\end{array}$} & \multirow{2}{*}{$\begin{array}{l}\text { Comparison } \\
\text { with the scheme } \\
\text { of work at the } \\
\text { reference date }\end{array}$} & \multicolumn{2}{|c|}{$\begin{array}{c}\text { Students' activities as } \\
\text { per COPUS }\end{array}$} & \multicolumn{2}{|c|}{$\begin{array}{c}\text { Teachers' activities as } \\
\text { per COPUS }\end{array}$} \\
\hline & & & & $\begin{array}{l}\text { Active } \\
\text { learning }\end{array}$ & $\begin{array}{l}\text { Passive } \\
\text { learning }\end{array}$ & Presenting & Guiding \\
\hline $001001 \mathrm{~F}$ & 3 June 2019 & Solubility curves & Behind 3 weeks & $65 \%$ & $30 \%$ & $56 \%$ & $28 \%$ \\
\hline 002001M & 13 June 2019 & $\begin{array}{l}\text { Categories of chemical } \\
\text { reactions }\end{array}$ & Behind 6 weeks & $78 \%$ & $19 \%$ & $42 \%$ & $57 \%$ \\
\hline 003001M & 14 June 2019 & Identification of ions & On track & $19 \%$ & $81 \%$ & $65 \%$ & $26 \%$ \\
\hline $004001 \mathrm{~F}$ & 31 May 2019 & Solubility of salts & Behind 1 week & $51 \%$ & $49 \%$ & $46 \%$ & $46 \%$ \\
\hline $005001 \mathrm{M}$ & 3 June 2019 & $\begin{array}{l}\text { Classification of elements } \\
\text { into metals, metalloids } \\
\text { and non-metals }\end{array}$ & Behind 4 weeks & $27 \%$ & $67 \%$ & $60 \%$ & $37 \%$ \\
\hline 006001F & 6 June 2019 & $\begin{array}{l}\text { Mole concept, relative } \\
\text { molecular mass (RMM) }\end{array}$ & $\begin{array}{l}\text { In advance } 4 \\
\text { weeks }\end{array}$ & $75 \%$ & $18 \%$ & $37 \%$ & $48 \%$ \\
\hline 007001M & 7 June 2019 & $\begin{array}{l}\text { Steps to effective waste } \\
\text { management }\end{array}$ & Behind 8 weeks & $43 \%$ & $33 \%$ & $30 \%$ & $23 \%$ \\
\hline 008001F & 12 June 2019 & $\begin{array}{l}\text { Categories of chemical } \\
\text { reactions }\end{array}$ & Behind 6 weeks & $75 \%$ & $22 \%$ & $25 \%$ & $69 \%$ \\
\hline 009001M & 5 June 2019 & Solubility curves & Behind 3 weeks & $52 \%$ & $44 \%$ & $76 \%$ & $24 \%$ \\
\hline 010001M & 12 June 2019 & $\begin{array}{l}\text { Mole concept, relative } \\
\text { atomic mass (RAM) }\end{array}$ & $\begin{array}{l}\text { In advance } 3 \\
\text { weeks }\end{array}$ & $41 \%$ & $49 \%$ & $44 \%$ & $50 \%$ \\
\hline
\end{tabular}




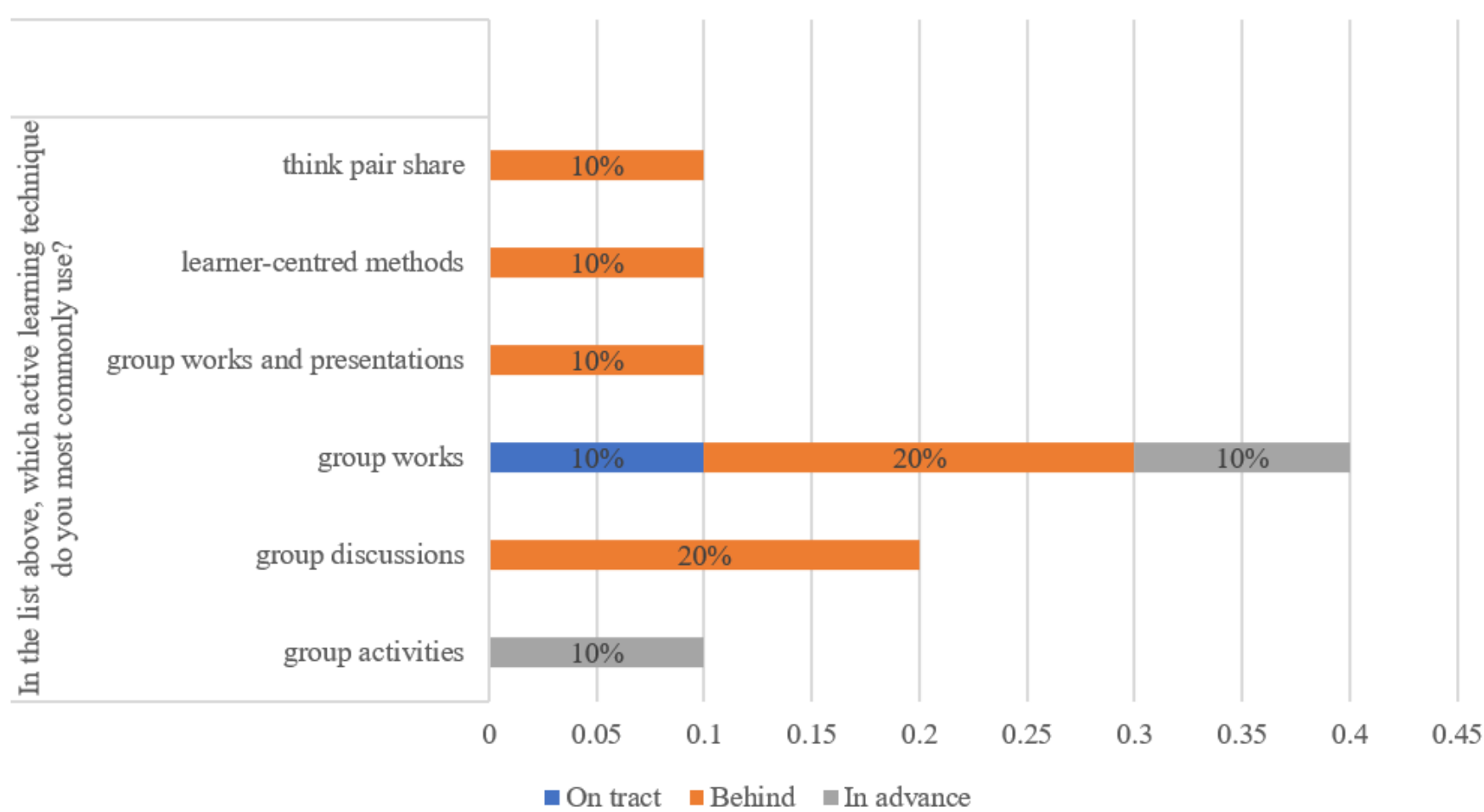

Figure 2. Teachers' self-reporting of most commonly used teaching techniques and their alignment with the district scheme of work

\section{CONCLUSION}

This study confirmed that chemistry teachers in S2 were aware of different active learning techniques for teaching chemistry in S2 classes but did not apply them. Teachers reported focusing too much on grouping students into small groups because of large class sizes. However, putting students in groups in itself does not indicate that active learning is taking place. Most teachers focused more on presentation than guiding students on what to do, and students spent much of their time listening to the teacher and taking notes.

The results of this study showed that there was not a relationship between passive learning in S2 chemistry classes and staying aligned with the district scheme of work for chemistry and those chemistry teachers who do employ active learning techniques were not necessarily behind the scheme of work.

We recommend further study to determine the real cause of the irregularities found in most of the selected teachers in terms of their alignment with the district scheme of work for chemistry. We also recommend more support for teachers to use active learning techniques in teaching chemistry in S2 in order to effectively implement $\mathrm{CBC}$ and allow active learning to take place when using group work-related activities.

\section{ACKNOWLEDGEMENTS}

This study was completed with the funding from ACEITLMS and was conducted with the approval of the Gasabo District in Rwanda. Thanks go to the district unit of education, the school administration of the selected secondary schools, and their S2 chemistry teachers and students. Thanks to Kizito NDIHOKUBWAYO, Oswald RUTAYISIRE and Elise DUSHIMIMANA for their comments on this study. Thanks to Claudine UWIRAGIYE, Mahé LIKA Alto, Stacey TONA Liana and Alva GABE Saggiy for your emotional support.

\section{REFERENCES}

Brandt, L., Elen, J., Hellemans, J., Heerman, L., Couwenberg, I., Volckaert, L., \& Morisse, H. (2001). The impact of concept mapping and visualization on the learning of secondary school chemistry students. International Journal of Science Education, 23(12), 1303-1313. https://doi.org/10.1080/ 09500690110049088

Bitektine, A. (2008). Prospective case study design: Qualitative method for deductive theory testing. Organizational Research Methods, 11(1), 160-180. https:/ / doi.org/10.1177/1094428106292900

Cahyana, U., Paristiowati, M., Savitri, D. A., \& Hasyrin, S. N. (2017). Developing and application of mobile game based learning (M-GBL) for high school students performance in chemistry. Eurasia Journal of Mathematics, Science and Technology Education, 13(10), 7037-7047. https://doi.org/10.12973/ ejmste/ 78728

Chee, Y. S., \& Tan, K. C. D. (2012). Becoming chemists through game-based inquiry learning: The case of 
legends of Alkhimia. Electronic Journal of E-Learning, 10(2), 185-198.

Creswell, J. W., \& Garrett, A. L. (2008). The "movement" of mixed methods research and the role of educators. South African Journal of Education, 28(3), 321-333. https:/ / doi.org/10.4314/saje.v28i3.25155

Davidson, N., \& Major, C. H. (2014). Boundary Crossings: Cooperative Learning, Collaborative Learning, and Problem-Based Learning. Journal on Excellence in College Teaching, 25, 7-55.

Eberlein, T., Kampmeier, J., Minderhout, V., Moog, R. S., Platt, T., Varma-Nelson, P., \& White, H. B. (2008). Pedagogies of engagement in science: A comparison of PBL, POGIL, and PLTL. Biochemistry and Molecular Biology Education, 36(4), 262-273. https:/ / doi.org/10.1002/bmb.20204

Eilks, I., Prins, G. T., \& Lazarowitz, R. (2013). Teaching Chemistry - A Studybook A Practical Guide and Textbook for Student Teachers, Teacher Trainees and Teachers. (G. and Ingo Eilks University ofBremen, I. Avi Hofstein Weizmann Institute ofScience, \& SENSE, Eds.), How to Organise the Chemistry Classroom in a Student-Active Mode". In How to Organise the Chemistry Classroom in a Student-Active Mode. AW Rotterdam, The Netherlands: Sense Publishers. https://doi.org/10.1007/978-94-6209140-5

Freeman, S., Eddy, S. L., McDonough, M., Smith, M. K., Okoroafor, N., Jordt, H., \& Wenderoth, M. P. (2014). Active learning increases student performance in science, engineering, and mathematics. Proceedings of the National Academy of Sciences, 111(23), 84108415. https:/ / doi.org/10.1073/pnas.1319030111

Imenda, S. N. (2018). On the Unity of Behaviourism, Cognitivism and Constructivism in Teaching and Learning. International Journal of Educational Sciences, 20(1-3), 86-95. https://doi.org/10.31901/ 24566322.2018/20.1-3.11

Kilic, A. (2013). Effects of Teaching Chemistry Using Concept Maps on Students ' Achievement in School Chemistry in India and.

Kousa, P., Kavonius, R., \& Aksela, M. (2018). Lowachieving students' attitudes towards learning chemistry and chemistry teaching methods. Chemistry Education Research and Practice. https:/ / doi.org/10.1039/C7RP00226B

Kristen, K., Malinda, W., Monica, D., \& Kendra, M. (2017). Pedagogical Methods and Technology Used in Chemistry Secondary Education. Modern Chemistry \& Applications, 05(03), 3-6. https: / / doi.org/10.4172/2329-6798.1000223

Lackamp, J. W. (2016). Case Study - Results at Primary School Leaving Examination in a Rural District in Rwanda, 15(9), 99-117.
Lund, T. J., Pilarz, M., Velasco, J. B., Chakraverty, D., Rosploch, K., Undersander, M., \& Stains, M. (2015). The best of both worlds: Building on the COPUS and RTOP observation protocols to easily and reliably measure various levels of reformed instructional practice. CBE Life Sciences Education, 14(2), 1-12. https:// doi.org/10.1187/cbe.14-100168

Maxwell, D. O., Lambeth, D. T., \& Cox, J. T. (2015). Effects of using inquiry-based learning on science achievement for fifth-grade students. Asia-Pacific Forum on Science Learning and Teaching, 16(21), 1-31. Retrieved from https://www.eduhk.hk/apfslt/ download/v16_issue1_files/cox.pdf

Michael, J. (2006). Where's the evidence that active learning works? Advances in Physiology Education, 30(4), 159-167. https://doi.org/10.1152/ advan.00053.2006

Musingafi, M. C. C., Mhute, I., Zebron, S., \& Kaseke, K. E. (2015). Planning to Teach: Interrogating the Link among the Curricula, the Syllabi, Schemes and Lesson Plans in the Teaching Process. Journal of Education and Practice, 6(9), 54-59. Retrieved from http:/ / search.ebscohost.com/login.aspx?direct=tr ue\&db=eric\&AN=EJ1082472\&site=ehost-live

Ndihokubwayo, K., \& Habiyaremye, H. T. (2018). Why Did Rwanda Shift from Knowledge to Competence Based Curriculum? Syllabuses and Textbooks Point of View. International Multi-Disciplinary, 12(50), 135 142. https://doi.org/10.4314/afrrev.v12i3.4

Oludipe, D., \& Awokoy, J. O. (2010). Effect of cooperative learning teaching strategy on the reduction of students' anxiety for learning chemistry. Journal of Turkish Science Education, 7(1), 30-36.

Paulson, D. R. (2009). Active Learning and Cooperative Learning in the Organic Chemistry Lecture Class. Journal of Chemical Education, 76(8), 1136. https:/ / doi.org/10.1021/ed076p1136

Pietzner, V. (2014). Computer-based learning in chemistry classes. Eurasia Journal of Mathematics, Science and Technology Education, 10(4), 297-311. https:/ / doi.org/10.12973/eurasia.2014.1084a

REB. (2015). Curriculum Framework: Pre-Primary To Upper Secondary 2015. Competence Based Curriculum. Kigali- Rwanda.

REB, R. E. B. (2016). DCC Committee Guideline (2).pdf.

Ruiz-Primo Schultz, S. E., Li, M. , Shavelson, R., M. A. (2001). Comparison of reliability and validity of scores from concept-mapping techniques, 38(2), 260-278. https://doi.org/10.1002/1098-2736(2001 02)38

Smith, M. K., Jones, F. H. M., Gilbert, S. L., \& Wieman, C. E. (2013). The classroom observation protocol for undergraduate stem (COPUS): A new instrument 
to characterize university STEM classroom practices. CBE Life Sciences Education, 12(4), 618-627. https:// doi.org/10.1187/cbe.13-08-0154

Sola, A. O., \& Ojo, O. E. (2007). Effects of project, inquiry and lecture-demonstration teaching methods on senior secondary students' achievement in separation of mixtures practical test. Educational Research and Reviews, 2(6), 124-132.
Stavridou, H., \& Solomonidou, C. (1998). Conceptual reorganization and the construction of the chemical reaction concept during secondary education. International Journal of Science Education, 20(2), 205221. https:/ / doi.org/10.1080/0950069980200206

Tenaw, Y. A. (2015). Effective strategies for teaching chemistry. International Journal of Education Research and Reviews, 3(3), 78-84.

\section{APPENDIX A}

\section{Teacher Survey}

\section{Section A: Biodata}

Dates: ... / ... / ... School code: ...., Class: .... Teacher's code: .... Gender: ....... (M or F)

No. of years teaching:

$\square 0$ - 1 year $\square 2$ - 3 years $\square 4$ - 5 years $\square 6$ - 9 years $\square 10$ - 19 years $\square$ over 20 years

\section{Section B: Most commonly used pedagogical techniques}

Part One (I):

1. Teacher's self-assessment or peer-assessment on using active learning and teaching technique:

$\square$ Beginner $\square$ Intermediate $\square$ Expert

2. How often do you use active learning and teaching technique?

$\square$ Daily $\square$ Weekly $\square$ Monthly $\square$ At least once a term $\square$ Never

Part Two (II): Show by circling the level of how you agree/disagree with the following statements (1. Strongly disagree; 2 . Disagree; 3 . Not sure; 4 . Agree and 5 . Strongly agree)

\begin{tabular}{|l|l|c|c|c|c|c|}
\hline & Statement & \multicolumn{3}{|c|}{ Responses } \\
\hline 3 & I am aware of different active-based learning and teaching techniques & 1 & 2 & 3 & 4 & 5 \\
\hline 4 & I am using active-based learning and teaching techniques & 1 & 2 & 3 & 4 & 5 \\
\hline 5 & I am aware of hands-on activities for S2 chemistry classes & 1 & 2 & 3 & 4 & 5 \\
\hline 6 & I am using hands-on activities for S2 chemistry classes & 1 & 2 & 3 & 4 & 5 \\
\hline 7 & I am using activity-based learning technique in learning and teaching S2 chemistry classes & 1 & 2 & 3 & 4 & 5 \\
\hline
\end{tabular}

Part Three (III): Answer the following questions

8. Mention at least three strategies that you normally use to enhance the academic performance of chemistry in S2.

9. Mention at least five active learning techniques that you do know

10. Which active learning technique do you mostly use in the list above:

At which frequency? _ _ every day _ _every week _ _every month 
11. Please tell us how often in the past 3 months have you used active learning and teaching technique in 52 chemistry classes:

__every day __every week _ _every month _ never

\section{APPENDIX B}

\section{Teacher's Interview Guide}

\section{Section A: Biodata}

Dates: .... / ... / ... School code: ......., Class: .... Teacher's code: .... Gender: ... (M or F)

No. of years teaching:

$\square 0$ - 1 year $\square 2$ - 3 years $\square 4$ - 5 years $\square 6$ - 9 years $\square 10$ - 19 years $\square$ over 20 years

\section{Section B: Most commonly used pedagogical techniques}

1. What are five active learning techniques that you do know?

2. In the list above, which one do teachers in your school use most?

3. Which one can you recommend to others and why?

\section{APPENDIX C}

\section{Classroom Observation Protocol for Undergraduate STEM - COPUS}

Smith MK, Jones FHM, Gilbert SL, and Wieman CE. 2013. The Classroom Observation Protocol for Undergraduate STEM (COPUS): a New Instrument to Characterize University STEM Classroom Practices. CBE-Life Sciences Education, Vol 12(4), pp. 618-627; www.cwsei.ubc.ca/resources/COPUS.htm

Date: _Llass: __ Instructor: __ No. students

Classroom

1. L-Listening; Ind-Individual work; CG-Clicker Q discussion; WG-Worksheet group work; OG-Other group work; AnQ-Answer Q; SQ-Student Q; WC-Whole class discuss.; Prd-Predicting; SP-Student present.; TQ-Test/quiz; W-Waiting; O-Other

2. Lec-Lecturing; RtW-Writing; FUp-Follow-up; PQ-Pose Q; CQ-Clicker Q; AnQ-Answer Q; MG-Moving/Guiding; 1o1-One-on-one; D/V-Demo+; Adm-Admin; WWaiting; O-Other

For each 2 minute intervals, check columns to show what's happening in each category (or draw a vertical line to indicate the continuation of activity). Check multiple columns where appropriate.

COPUS

\begin{tabular}{|c|c|c|c|c|c|c|c|c|c|c|c|c|c|c|c|c|c|c|c|c|c|c|c|c|c|c|c|c|c|}
\hline \multirow[b]{2}{*}{$\min$} & \multicolumn{13}{|c|}{ 1. Students doing } & \multicolumn{12}{|c|}{ 2. instructor doing } & \multicolumn{3}{|c|}{$\begin{array}{c}3 . \\
\text { Engagement }\end{array}$} & \multirow{2}{*}{$\begin{array}{l}\text { Comments: EG: explain difficult coding choices } \\
\text { flag key points for feedback for the instructor } \\
\text { identify good analogies, etc. }\end{array}$} \\
\hline & $\mathrm{L}$ & $\begin{array}{l}\text { In } \\
\mathrm{d}\end{array}$ & $\begin{array}{l}C \\
G\end{array}$ & $\begin{array}{l}W \\
G\end{array}$ & \begin{tabular}{|l|}
$\mathrm{O}$ \\
$\mathrm{G}$
\end{tabular} & $\begin{array}{c}\text { An } \\
Q\end{array} S$ & SQ & $\begin{array}{l}\text { W } \\
\text { C }\end{array}$ & \begin{tabular}{c|}
$\mathrm{Pr}$ \\
$\mathrm{d}$
\end{tabular} & SP & $\begin{array}{l}\mathrm{T} / \\
\mathrm{Q}\end{array}$ & W & $\mathrm{O}$ & Lec & $\begin{array}{l}\text { Rt } \\
W\end{array}$ & $\begin{array}{c}\mathrm{Fu} \\
\mathrm{p}\end{array}$ & $P Q$ & $\mathrm{CQ}$ & $\begin{array}{c}\text { An } \\
Q\end{array}$ & $\begin{array}{l}M \\
G\end{array}$ & 101 & $\begin{array}{l}\mathrm{D} / \\
\mathrm{V}\end{array}$ & $\begin{array}{c}\mathrm{Ad} \\
\mathrm{m}\end{array}$ & W & $\mathrm{O}$ & $\mathrm{L}$ & M & $\mathrm{H}$ & \\
\hline \multicolumn{30}{|l|}{$0-2$} \\
\hline \multicolumn{30}{|l|}{2} \\
\hline \multicolumn{30}{|l|}{4} \\
\hline \multicolumn{30}{|l|}{6} \\
\hline \multicolumn{30}{|l|}{$8-10$} \\
\hline & $\mathrm{L}$ & $\begin{array}{c}\text { In } \\
\mathrm{d}\end{array}$ & $\begin{array}{l}C \\
G\end{array}$ & $\begin{array}{l}W \\
G\end{array}$ & $\begin{array}{l}\mathrm{O} \\
\mathrm{G}\end{array}$ & $\begin{array}{c}\mathrm{An} \\
\mathrm{Q}\end{array}$ & SQ & $\begin{array}{l}\text { W } \\
\text { C }\end{array}$ & $\begin{array}{c}\operatorname{Pr} \\
d\end{array}$ & SP & $\begin{array}{l}\mathrm{T} / \\
\mathrm{Q}\end{array}$ & W & $\mathrm{O}$ & Lec & $\begin{array}{l}\text { Rt } \\
\text { W }\end{array}$ & $\begin{array}{c}F u \\
p\end{array}$ & $P Q$ & $\mathrm{CQ}$ & $\begin{array}{c}\text { An } \\
\text { Q }\end{array}$ & $\begin{array}{l}M \\
G\end{array}$ & 101 & D/ & $\begin{array}{c}\text { Ad } \\
\mathrm{m}\end{array}$ & W & $\mathrm{O}$ & L & M & $\mathrm{H}$ & \\
\hline $\begin{array}{c}10- \\
12\end{array}$ & & & & & & & & & & & & & & & & & & & & & & & & & & & & & \\
\hline
\end{tabular}

